\title{
FLEXIBLE USE OF TIME TO OVERCOME CONSTRAINTS
}

\author{
A time-geographical discussion about power and flexibility
}

\section{Elin Wihlborg}

National Institute for Working Life, Norrkoping, Sweden and Department of Political Science, Luleå University of Technology, Sweden

\begin{abstract}
Flexibility is often a keyword for people working in project-oriented organisations. It definitely influences their everyday life, since they are expected to be available and engaged anytime and anywhere and often with different types of obligations. However, there are constraints limiting people's possibilities in every specific time-space. The time-geographical perspective provides concepts for analysing constraints, by identifying: capacity, coupling, steering or authority constraints. The aim of this paper is to discuss the timegeographical concept of constraints and analyse how they are overcame by a flexible use of time. The paper is based on two field studies. The first was conducted in twelve households and included in-depth interviews at two occasions and in between the household members wrote time-diaries during a week. The second was more extensive. Two focus groups, each with 24 persons, who all had written time-diaries, were interviewed. The conclusion of these studies is that different forms of constraints define the outcome of flexibility and that the use of time can be an expression of power.
\end{abstract}

Key words: Time-space, flexibility, power, constraints.

\section{INTRODUCTION}

Flexibility is often a keyword for people working in project-oriented organisations. It definitely influences their everyday life, since they are expected to be available and engaged anytime and anywhere and often with different types of obligations. Without clear and defined working hours and a single working place, there are always possibilities for choice - where, 
when and how you should fulfil your job-related obligations. The home is a time-space pocket given new meanings when hosting work related activities.

However, there are constraints limiting people's opportunities in every specific time-space. What activities that can be conducted depends on how the local time-space pocket is organised, what resources are available and accessible to the individual and which constrains $\mathrm{s} / \mathrm{he}$ experiences in the actual situation. Daily life is very much characterized of routines. Routines are activity patterns that we conduct almost without reflecting about why and how. However, if there are many opportunities for different ways of conducting daily life, people are not bound by routines. Instead the individual makes choices of how, when and where to perform different things during the day. Such choices are very much a result of the individuals' power to form their own life. S/he becomes more aware of their activity patterns, since s/he has to consider different possibilities and clearly motivate their choices. In such situations the individual pays more attention to constrains, since they experience them more clearly when they are no longer hidden by daily routines.

Time-geography is focusing the individual's activity patterns in the timespace. Constrains are divided into three categories related to the individual's own capacity and co-ordination with others as well as constraints set up by restrictions that have the legal power to steer the individual.

For time-geographical studies a specific method of time-diaries has been developed to make the daily activity patterns, as well as spatial and social contexts, visible. Thus the embedding of activities in time space can be analysed from the patterns of what people do rather than what they say they are doing and both unreflected and conscious constraints can be analysed. However, since time-geography do not attempt to explain why the outcome in time space is as it is, I will here try to develop the understanding of power by dividing and specifying the constraints and briefly apply them to flexibility and the use of ICT.

\section{METHOD AND MATERIAL}

This paper emanates from two field-studies. The first was more intensive, since I there followed twelve households with a more in-depth approach. The second was more extensive since one person from each of the study's twenty-four households participated and they were interviewed in small focus-groups. In both studies I have worked with a combination of timediaries and in-depth / focus groups interviews.

The method has been developed from the time-geographical time-diary studies (see among others Ellegård 1993; 1994; 1999; Friberg 1990; 1998; 
Ellegård \& Nordell 1997; Ellegård \& Wihlborg 2001). This method is based on an ambition to find out what people do instead of what they say they are doing. By letting them fill in simple diary sheets answering the questions: where, when, what they do, together with whom and some comments, the researcher gets a picture of their activity patterns, social interaction and movements. The method is based on time-geography, which combines the dimensions of time and space and sees them as inseparable. A crucial issue for the founder of the time-geography, Torsten Hägerstrand (se among other $1974 ; 1985)$ was the ambition to develop a notation system, which could grasp and combine observations in its time-space context (Hägerstrand 1974:88). Thereby time-space interaction was illustrated as trajectories where the map is the base (horizontally) and time develops upward (vertically). The time-diaries are seen as field notes and are converted into expressive illustration of the perspectives: time-space, time-activity and time-social contacts. The analytical tool for the time-activity dimension has been developed by Ellegard and Nordell (1997) and the different types of activities are categorized into seven main spheres. Each sphere includes about 100 activities combined in different groups. The main spheres of activities are: Care for one self, Care for others, Household care, Recreation and reflection, Movements and transportation, Procure and prepare food, Gainful employment and School work.

The complex patterns which are made visible through the time-space notation system also open up for comparison between households over time. However, the illustrations of what the informants have noticed in their time diaries say very little about the reasons behind the different activity patterns, social contacts and movements. Therefore we have found it essential to combine the time-diaries with different forms of interviews (Westermark 2003; Nordell 2002; Wihlborg et. al.2003). I made two interviews with each household in their home. The first time I introduced the study and the timediary and it provided me also with an on-site observation, mapping the basic context of the household, which was useful for making a relevant analysis of their time-diaries. The follow-up interviews were more reflective, beginning with spontaneous responses to the time-geographical illustrations of their days and then continuing with discussions about the reasons for their choices in specific situations. Mannberg (2004) has raised the demand for a triangulation of methods by using the first interview as a life-story.

Both field studies are based on this three steps interaction with the households/individuals: interview, time-diary and reflective interview. The households in the in-depth field-study were chosen to illustrate different degrees of flexibility in their paid work. Since all these interviews have taken place in the home of the participants I did bring food (dinner or lunch 
depending on time of the day). ${ }^{\prime}$ This group have totally noted about three thousands activities in their time-diaries.

The participants in the second field study had very diverse life situations, since they were students taking part in a part time course at the university. Some of them worked fulltime at the same time, others were full-time students whereas others had part-time employment or were self employed at the same time. However, they all had to be flexible to fit in the course which was given on different days and times and demanded a high degree of own work. These differences in life situation of the participants made the discussions in the focus-groups very dynamic. Each focus-group included eight persons and the groups were set up to be different regarding gender, age and household composition. During the first meeting we discussed the participant's expectations and their experience of being flexible enough to fit the university course into their daily life as well as some practical matters like how to deal with the time-diary. In their preparation for the second meeting they were asked to write down, based on their time-diaries, some reflections regarding: use of information technology, physical movements, and situations where they considered themselves as flexible. These reflective papers then formed the base for our second focus-group interview.

It is difficult to evaluate if the sample of households and individuals is scientifically valid since it is indeed a very qualitative study. The introduction of the study was based on quite vague research questions supported only by the potential benefits of the method and without any clear hypothesis. Therefore I could neither define factors that could be regarded as dependent and relevant nor could I select households that were representative without knowing what they should represent.

\section{TIME-SPACE AND IT'S CONSTRAINTS}

Time-geography is not a theory as such. It is rather an ontological perspective, suggesting that everything takes place and time, regardless if it is a person or a thing, and that humans and their contexts (physical, social and mental) are inseparable (Hägerstrand, $1974 ;$ 1985).

${ }^{1}$ This should also been seen as a small compensation for their participation since they did not get any economic compensation. 


\subsection{The time-geographic perspective}

Time-geography has developed from geography and therefore the physical world and the human utilization of it, is in focus (Hägerstrand, 1993). Timespatial relations between phenomena of different kinds are important in time-geography (Hägerstrand, 1985). There is a co-existence in time and space, since everything takes place somewhere on the earth's surface, and takes time to happen. These essential observations are the ground for the time-geographical basic processes orientation (Hägerstrand, 1974; Lenntorp, 1976). The process approach of time-geography underlines the importance of not only the events going on, but also of the existence of relics of past events and of seeds for future events immanent in present ones (Hägerstrand, 1974). The present now is continuously transformed into past situations. From an individual perspective this process includes the overcoming of constraints and an identification of what opportunities these offer depending on what has been done and what the plans are for the future.

\subsection{The Problem of Power}

Time-geography has been criticised for not making power relations visible. But as I stated in the discussion about methodology, time geography has so far mainly been concerned with issues like what is happening, when and where, rather than with the question of why. Therefor a time-geographical analysis usually stops with a description of the outcome in time-space without exploring the reasons that could be provided by an analysis of power. Giddens formulates this critic when he writes:

... time-geography involves only a weakly developed theory of power. /... / both vaguely formulated and invoke a zero-sum conception of power as a source of limitations upon action. (Giddens 1984:117)

Hägerstrand's weak and actually quite uninteresting discussion of power can be seen as a consequence of the fact that he was satisfied when he had established the notation system. (The notation) This system was his main aim - not to explain the reasons behind what is represented in the notations of time-space. However, now that the notation system is there, we must consider why time-space is organised in the way it is. Thus I will try to develop Hägerstrand's concepts of constraints further by opening for a discussion about power. I will do this by dividing and defining the concepts of constraints that Giddens points out as being the ones closest to the discussion of power in time-geography, when he states that: 
If power is conceived as generative, on the other hand, the 'constraints' of which Hägerstrand speaks are all modalities for the engendering and sustaining of structure of domination. (Giddens 1984:117)

Hägerstrand himself makes a useful distinction between capacity constraints related to the individual. But, when it comes to the individual's more complex relations and thereby also to the compound constraints of relations to others in a social and physical context, he only provides a vague explanation. Therefore I will here try to show how the structures of dominance are articulated as consequences of power in time-space.

\subsection{Constraints of our capacity}

Hägerstrand (1985) begins with the individual person in her time-space context and focus on her capacity to act limited only by the most basic capacity constraints. Capacity constraints are, however, everything that limits the individual's actions, and that could be deduced to the capacity of herself or the tools she posses. There are three different types of capacity constraints. First the biological capacity constraints, such as the need for rest and food at certain intervals and sometimes even medical restrictions like having a cold for a short period of time or life time capability constraints by a disability. The biological limits are integrated with the body and are related to the nature of human beings. Also bound to the human being, but much more different between individuals, are the mental or intellectual capacity constraints. These are limiting her capacity to understand and cope with the information given, since knowledge (both theoretical and tacit) is restricted. Over a life time individuals continuously develop, more or less, mental and intellectual capacity in order to be able to overcome these constraints. We learn to speak, read and write and how to fit in to different social situations. Mental and intellectual capacity constraints are more contextually dependent ${ }^{2}$ than are the biological capacity restrictions. The last form of capacity constraints, that Hägerstrand (1985) identifies, is the spatial capacity constrains, which limit our reach in time-space. For example, one can decide to sit on a chair next to the computer (not reaching any further in the real space (not virtual spaces)) or walk to the café (reach a spaces where other needs could be met) and if using any tools (bike, car, bus or...) less time is needed to reach the same positions. By having access (depends on coupling constraints) to tools for travelling or communication, like telephone

\footnotetext{
${ }^{2}$ We all have the experiences of not understanding a social context that we have experienced, for example being a tourist and not understanding the native language and cultural codes.
} 
and e-mail, the spatial capacity is increased and the person can reach further in space in the same time.

\subsection{Coupling constraints}

Coupling restrictions is everything that limits the individual's co-ordination with other people and physical artefacts. Dealing with coupling constraints is a process of co-ordination. In the notation system the connection between people and artefacts is obvious and very often in focus. Thus it is important to separate coupling constraints into two groups covering coupling to other humans and to physical artefacts respectively, since other humans have the power to manipulate our coupling constraints, whether these can facilitate the coupling or not. The powers expressed by humans are deliberate.

Our possibilities to connect with other human beings depend on the other person's willingness to be connected with. This is not the case when it comes to "dead things" as physical artefacts. In the latter case it mainly depends on our own coupling abilities, such as being able to catch a train. The train as such has no resources to constrain our possibility to catch the train. However, other human actors can facilitate our possibilities to grasp physical things.

When it comes to co-ordinating with other people, they have the power to decide, if they wish to facilitate our connection effort or make it more difficult. We can influence upon other persons coupling constraints by using power. Being late for a meeting forces the other party to wait (or give up waiting after a certain period of time). Then it is not just a question of coupling possibility but also of which of the parties concerned that has the power in this specific situation. The power to connect is essential for timegeography since it is very much an issue of usage of the time space.

\subsection{Authority constraints}

Steering or authority constraints are defined by Hägerstrand (1985) as everything that has a legal power to steer the individual's actions and thereby limit her action space. Authority constraints are controlling different actors' access to time-space and thereby the power of these actors is obvious. The authority constraints are limiting our access to the space and thereby also our use of time, since they define which time-space that is accessible for us (Åqvist 1992). Opening hours for shops and other service places, for example, are authority constraints for our access to the activities that we can conduct there.

In order to understand the authority constraints we have to understand power. Since Hägerstrand's conceptualisation of power is vague, I will deal 
with the complex discussion of power by applying three different broad conceptualisations of power. This is a huge theoretical discussion and I will not be able to make a full coverage neither in this paper nor in a longer profound discussion. The following should thus be seen as a first attempt to deepen the time-geographical problematization of power.

The most basic way of understanding power was put forward by Dahl (1957) stating that A has power over B, when $s /$ he makes B do what B otherwise would not have done. This is an explanation of power that does not consider the context and regards the parties as equally able to negotiate. It is only useful for explaining really simple situations and therefore it can be used to explain situations clarified revealed by the time-geographical notation system since it disregards the relation as such. Thus authority constraints can first of all be seen as those brought about by other individuals' power over us in a specific pocket of time-space.

There are, however, no such equal relations were power can be freely negotiated. The actors always have access to different resources, which they use in order to get what they want. The actors in a specific power situation also have a history of former experiences and desires as well as access to resources, which can give them the power in the specific situation. The use of resources have to be legitimate; otherwise there will be legal reprimands of using the resources. There are of course always risks that someone should use their resources in a non-legitimate way such as theft or violence, but to keep it simple. I'm disregarding such alternative possibilities in this paper. The legal use of resources to gain power provides opportunities for legally based authority constraints towards others. What is legal in a society, is determined by those of it's institutions that are structuring it's organisation (see among others Giddens 1984). Here power is the complex inter-relation between actors, their resources and their utilisation of institutions and social construction of resources.

Institutions can be both formal, such as legal rules, and informal, such as cultural norms and praxis (North 1990). Informal institutions are also considered as power in the society, but more implicitly. For the conception of constraints in this meaning we have to turn to Foucault's more discursive understanding of power. This is a form of power that regulates and controls human thoughts and behaviour and it is thereby the product of informal institutions in the society. Foucault argues that power just can be exercised and exists in action (Kelly 1994). In meaning no one can per se have power. Applying this perspective of power to the discussion of constraints, we have to be aware of constraints expressed through actions legitimated by cultural norms and dominating discourses seen as informal institutions. Power, in this meaning, regulates and controls human behaviour. The outcome of 
power is made visible at first through the human being's pattern of activity, which is in focus for the time-geographical notations system.

\subsection{Summing up the constraints}

The capacity constraints are found within the individual herself and can be expressed as the power her capacity has over her possibilities to act. Coupling constraints are either dependent on possibilities to connect to others or, if the other is a human being, that person's expression of power through her willingness and ability to connect. Finally, the authority constraints are defined by other individuals and social structures, legal and discursive.

Table 1. Summary of my view on different forms of time-geographical constraints

\begin{tabular}{|l|l|}
\hline Capacity constraints & $\begin{array}{l}\text { Biological capacity constraints } \\
\text { Mental and intellectual capacity constraints } \\
\text { Spatial capacity constraints }\end{array}$ \\
\hline Coupling constraints & $\begin{array}{l}\text { Constraints coupling to other human beings } \\
\text { Constraints coupling to physical artefacts }\end{array}$ \\
\hline Authority constraints & $\begin{array}{l}\text { Authority constraints expressed by other individuals } \\
\text { power over us } \\
\text { Authority constraints expressed by legal rules (formal } \\
\text { institutions) } \\
\text { Authority constraints expressed in actions by cultural } \\
\text { norms and dominating discourses (informal } \\
\text { institutions) }\end{array}$ \\
\hline
\end{tabular}

The aim with this division into different forms of constraints is to show how power is an aspect of the constraints. These constraints are limiting access to resources and individuals are using time and other resources to prevail over them. I will now briefly apply this view on power and constraints to analyse my time-geographical field-works on flexibility.

\section{TO BE FLEXIBLE AND/OR HAVE FLEXIBILITY - A QUESTION OF CONSTRAINTS}

Flexibility can both be a personal characteristic and also a characteristic of the situation in which the individual acts. In other words you can be flexible 
and you can have flexibility (Bekkengen 1999). These two aspects of flexibility are in different ways limited by (the different) various constraints.

Flexibility is often seen as a positive quality or characteristic of a person, but being flexible is also demanding (Blocklehurst 2001). If flexible means 'not being bound to routines' it takes a lot of time and other resources to make new decisions continuously. If being flexible means 'to have competence to do different things' then there is also a demand for resources.

\subsection{Capacities to be and have flexibility}

To be flexible is a personal capacity in itself and the participants in my studies showed that they had different built-in personal capacities to work in a flexible manner. Many of the part-time students, who had to take on the course in order to keep their jobs, expressed biological capacity constraints. They did not manage to study in the evenings after a full day of teaching themselves. Their bodies had the power (biological and mental capacity constraints) to prevent them from working any more. They expressed this as an obvious but, for many of them, unexpected constraint.

To be flexible they also spent remarkable amounts of time commuting, especially the days of the course. Travelling is a concrete example of handling spatial capacity constraint and it takes time to overcome the spatial capacity constraints. Their possibility to have spatial flexibility was constrained by where they lived. The reallocation of time from other activities to travelling is an expression of power since they thereby also defined their priorities. ICT was sometimes used to overcome the spatial capacity constraints, but as shown in many other studies, this could not fully compensate face-to-face interaction - there are other intellectual capacity constraints of communication when mediated. Technology can make people more flexible, but communication is constrained when mediated. Therefore they have to put efforts into the development of resources such as routines for communication, trust and technical competence. It takes time to develop such skills. Competence for communication is culturally constructed and therefore highly contextual as well. Learning is a way to handle the capacity constraints of the technology and thereby to enlarge the power to manage technology.

\subsection{Flexible coupling}

The capacity to connect to other is essential and the participants who worked from home showed how their flexibility improved their opportunities and encouraged them to couple with other things and people. Working from home using ICT gave flexibility to reach domestic equipment during work- 
hours. This became obvious from the time-geographical notation based on their time-diaries, where short periods appeared in the column for "household work" breaking up the main activity: paid work. Typical household work project was to handle laundry including activities such as starting the washing machine, emptying, hanging and ironing. Thereby the person could couple to the apparatus at home, only restricted by a weak coupling constraint to reach an artefact as compared to if $s /$ he had been working away from home. Making the laundry is an example of a project that takes more time than it needs attention from the person conducting it and therefore flexibility allowed it to be integrated with the paid work. One woman paid special attention to her management of these coupling constraints and saw the benefit of flexibility when comparing with the need to do all the laundry during weekends. She did not save time, but integrated activities and thereby she did not have to spend time neither to overcome spatial capacity constraints nor to overcome coupling constraints regarding artefacts.

Couple constraints related to other human beings and to organisations associated with the job can increase when tele-working. The informants in the intensive study had a need for technology, like using e-mail and telephones not just for specific information, but also for social reasons like saying good morning and telling colleagues that I'm working today, all as if they were doing some small talk in the office. Here coupling constraints could occur, however, when those being in the office didn't appreciate these contacts. Receiving a reply to a "good-morning" mail in late afternoon was almost insulting and gave a feeling of being excluded from the group spirit by the power expressed by the colleagues.

However, coupling to other people and to organisations other than those related to the work, were often facilitated by flexible working hours. Coupling to friends and even to services became much easier when they had the flexibility to spend the time as they wanted, as compared to working seven to four. Access to flexibility decreased the strength of the coupling constraints, since the informants could organize their use of time as they wanted.

\subsection{The power to be flexible and to have flexibility}

Everyone who expressed that they had experienced flexibility saw it as a power resource in the relations at the workplace. They could define their own action space and time-use. The ones in high positions within the company or the self-employed could define themselves what to do. They had power to administrate their own days and time - they were empowered. The flexible tele-workers had the power to do what they wanted in relation to 
others; they could prevail over authority constraints imposed upon others. They also had legal opportunity to work when and where they wanted and in addition cultural norms strengthened these opportunities, since there is a discourse between positive values and flexible work. This positive discourse gave them power when acting in relation to others since this is considered a desirable organisation of everyday life. Thus all aspects of the authority constraints related to their work were weak and they had all immense flexibility. On the other hand the legal authority constraints on the substance of work were, according to many of those with a flexible work, regarded as weak. This since they seldom had a clear agreement about the amount of work that was to be made and that they actually demanded more legal power from their employer in order to be able to feel satisfaction in their work. None really expressed any power to make them work more and spend less time on leisure activities. But through their use of time the discursive power is expressed.

On the other hand the shift-time workers lacked the power to overcome such constraints. They had no power to define their working hours themselves and the authority constraints were strong. Instead they needed a supportive home context to be flexible enough to come to work on a given schedule. Thus they had to have personal power to make others keep up at home for them when working odd hours, for example: taking care of children in the mornings of one week and at nights during the other. This is an authority constraint they practiced towards other individuals. They developed power to construct authority constraints on family and friends in order to make their everyday life flow smoothly. Their actions are outcomes of the strong and dominating discourse of paid work and the norm of having a job. Therefore they could keep up their power in relation to others, since the discursive power supported their organisation of everyday life.

\section{IT TAKES TIME TO PREVAIL OVER CONSTRAINTS - CONCLUDING REMARKS}

The participants made more or less conscious and more or less flexible use of time for handling daily constraints. Time is no constraint for household activities and choices. They all have 24 hours a day, and time is thus no variable constraint. It is rather the amount of activities people try to press in within their limited time-space that gives an impression of time as a constraint. Time can rather be seen as an integrated part of all the constraints, not at least since time is used to overcome the constraints. Time is used as a flexible resource that can open for many different ways of fulfilling a specific project by setting together different activities (Fitzpatrick 
2004). Time itself is often enough to overcome the basic capacity constraints. You can sleep, study or walk far away to prevail these constraints. But time has to be combined with other resources, which are often extracted from artefacts or social institutions in order to overcome the more complex authority constraints. These authority constraints and the power they articulate also vary between different time-space pockets. The construction of power is always contextual.

The late modern society characterized by globalisation, consumption and 'the new economy' is aiming for the liberation of the individual person from everything that can limit her creativity and free choices of life (Jørgensen 2004). Therefore the discursive authority constrains are less obvious in the late modern era. This means that the possibility of having flexibility is greater. The more complex the society is the more tools are within reach for the individual. Thereby her capacities can develop in many different ways. However, since all human beings have these possibilities, the individually based authority constraints will increase whereas the discursive authority constraints, on the other hand, will allow more differences and thereby open up for flexibility without constraints.

Finally we must be aware of that there are always compromises made in view of the fact that we have to live with lots of constraints. There are compromises based on how flexible you can and will be and how much flexibility you have and want to use. Possibilities to be flexible are mainly restricted by capacity constraints. To have flexibility is rather an issue of authority constraints. The coupling constraints are limiting both the individual capacity and the importance of the authority constraints. The ambition to handle the constraints depends on the individual's personal sense of what is a good life.

\section{REFERENCES}

Bekkengen, Lisbeth (1999) "Män som "pappor" och kvinnor som "föräldrar"". In: Kvinnovetenskaplig Tidskrift, vol 20, nr. 1 pp. 33-48.

Blocklehurst, Michael (2001) "Power, Identity and New Technology Homeworks: Implications for 'New forms' of Organizing". In Organization Studies, may 2001.

Dahl, Robert A. (1957) "The Concept of Power" Behavioral Science/ Journal of the Society for General Systems Research. No 3: 201-215.

Ellegård, Kajsa (1993) Olikadant. Aspekter på tidsanvändningens mångfald. Occasional Papers 1993:4. Kulturgeografiska institutionen. Göteborg: Göteborgs universitet.

Ellegård, Kajsa (1994) Att fånga det förgängliga. Utveckling av en metod för studier av vardagslivets skeenden. Occasional Papers 1994:1. Kulturgeografiska institutionen. Göteborg: Göteborgs universitet.

Ellegård, Kajsa (1999) A time-geographic approach to the study of everyday life of individuals - a challenge of complexity. In: GeoJournal vol 48 no 3 1999, Special issue on 
"Actors, activities and the geographical scene, Studies on time-geography, mobility and gender."

Ellegård, Kajsa och Nordell, Kersti (1997) Att byta vanmakt mot egenmakt. Stockholm: Anderssson \& Skyttemo.

Ellegård, Kajsa och Wihlborg, Elin (2001) Fånga vardagen. Ett tvärvetenskapligt perspektiv. Lund: Studentlitteratur.

Fitzpatrick, Tony (2004) “Social Policy and Time” In: Time \& Society, vol. 13, pp 197-219.

Friberg, Tora (1990) Kvinnors vardag. Om kvinnors arbete och liv. Anpassningsstrategier $i$ tid och rum. Lund: Lund University Press.

Friberg, Tora (1998) Förflyttningar, en sammanhållande länk $i$ vardagens organisation. (KFB-rapport 1998:23). Stockholm: KFB.

Giddens, Anthony (1984) The Constitution of Society. Cambridge: Polity Press.

Hägerstrand, Torsten (1974) "Tidsgeografisk beskrivning - syfte och postulat". In: Svensk geografisk årsbok, 86-94.

Hägerstrand, Torsten (1982) "Diorama, path and project". In: TESG Tijdschrift voor economische en sociale geographie. Journal of economic and social geography. 1982 lxxiii nr 6.

Hägerstrand, Torsten (1985) Time-Geography: Focus on the Corporeality of Man, Society, and Environment. New York: The United Nations University.

Jørgensen, Carsten René (2004) Psykologin i senmoderniteten. Stockholm: Liber AB.

Kelly, Michael (ed.) (1994) Critique and Power. Cambridge, MA: MIT Press. Including Foucault, Michel "Two Lectures".

Lenntorp, Bo (1976) Paths in space-time environments. A time-geographic study of movement possibilities of individuals. Lund: Gleerup.

Mannberg, Mariann (2004) 'Tidsgeografisk triangulering. Om tidsgeografin som kombinerad samhallsvetenskaplig metod". In: Ellegård, Kajsa \& Wihlborg, Elin Tidsgeografiska perspektiv. Tema T working paper. Linköping: Linköpings universitet.

Nordell, Kersti (2002) Kvinnors hälsa. En fråga om medvetenhet, möjligheter och makt. Göteborgs universitet.

North, Douglass C. (1990) Institutions, institutional change, and economic performance. Cambridge: Cambridge University Press.

Tietze, s. (2002) "When "works" come "Home": Coping Strategies of Teleworkers and their Families." In: Journal of Business Ethics. 41, pp 385-396.

Westermark, Asa (2003) Informal livelihoods: Women making and reflecting upon their biographies. A time geographic analysis in urban Colombia. Dept of Human and Economic Geography. Göteborg: Göteborg university.

Wihlborg, Elin, Jessica Rahm och Kajsa Ellegård (2003) Konvergerande teknik kommer hem. (Tema-T Arbetsnotat 272). Linköping: Tema Teknik och social förändring, Linköpings universitet.

Aquist, Ann-Cathrine (1992) Tidsgeografi $i$ samspel med samhällsteori. Lund: Lund University Press. 